\title{
Isolated Sphenoid Sinus Disease- A Unique Case of Sphenoidal Mucocoele
}

\author{
Tushar Kanti Ghosh, ${ }^{1}$ Srijoy Gupta, ${ }^{1}$ Pradeep Devineni ${ }^{1}$
}

\begin{abstract}
Introduction
Isolated Sphenoid Sinusitis and sinus lesions is a rare entity accounting for just 1-3\% of all sinus afflictions. Most occur in men in the third or fourth decade of life.

Case Report

A case of right sphenoid sinus mucocele is reported in a male patient aged 68 years, with size of the lesion $(35 \times 34 \mathrm{~mm})$ detected by CT \& MRI scans. The patient presented with a 3 weeks history of unilateral ptosis, diplopia, and photophobia. He also complained of bilateral nasal obstruction, nasal stuffiness, and a mucoid nasal discharge. Endoscopic decompression of the right sphenoid sinus was performed, and approximately $160 \mathrm{ml}$ of thick mucoid secretion was aspirated. Despite the size of the mucocele, no significant destruction of the sphenoid walls was evident. Postoperatively within 15 days the patient's symptoms improved significantly.

Conclusion

The Nasal Endoscope has revolutionised sphenoid sinus mucocele treatment. An adequate sphenoidotomy and drainage give excellent results.

$\underline{\text { Kevwords }}$

Mucocele; Sphenoid Sinus; Ophthalmoplegia
\end{abstract}

ABSTRACT

I solated sphenoid sinus mucocele is mainly inflammatory in origin with neoplasms being rare. Isolated sphenoid sinusitis accounts for $1-2 \%$ of all sinus infections. ${ }^{1}$ Mucoceles are defined as an accumulation and retention of mucus within a sinus as a result of an obstructed outlet. ${ }^{2}$ When the contents are purulent, the condition is referred to as pyocele. ${ }^{2}$ Posterior ethmoid and sphenoid sinus mucoceles and pyoceles can present with orbital complications such as superior orbital fissure syndrome or orbital apex syndrome requiring urgent drainage and evacuation. Rarely intracranial extension has also been reported. ${ }^{3}$

\section{Case Report}

A 68 years of age, male presented to us with a 3 week history of unilateral ptosis, diplopia and photophobia which was worsening. It was associated with nasal obstruction, nasal stuffiness and a mucoid discharge from nose which had been going on intermittently for more than a year. A mild DNS to the left side was found in the clinical examination of the patient along with signs of right Oculomotor (3rd cranial nerve) palsy (Fig. 1), ptosis (due to weakness of levator palpebrae), diplopia (due to weakness of the extra ocular muscles supplied by the 3rd nerve) and photophobia (due to defective parasympathetic pupillary innervation). Nasal endoscopy showed thick purulent discharge from the right superior meatus region along with a deviated nasal septum to left.

CT scan was suggestive of isolated sphenoid sinusitis. (Fig. 2) Bony septum and roof appeared intact. MRI scan was suggestive of a dilated sphenoid sinus with thick fluid collection inside indicating a sphenoid mucocele. (Fig. 3) It measured about $3.5 \times 3.4 \mathrm{~cm}$ in size. It appeared to be compressing the structures near the right orbital apex.

All the routine investigations were within normal limits for the patient.

The patient underwent endoscopic sinus surgery

1 - Ghosh ENT Foundation, Saltlake, Kolkata.

Corresponding author:

Dr Srijoy Gupta

email: srijoy89@gmail.com 


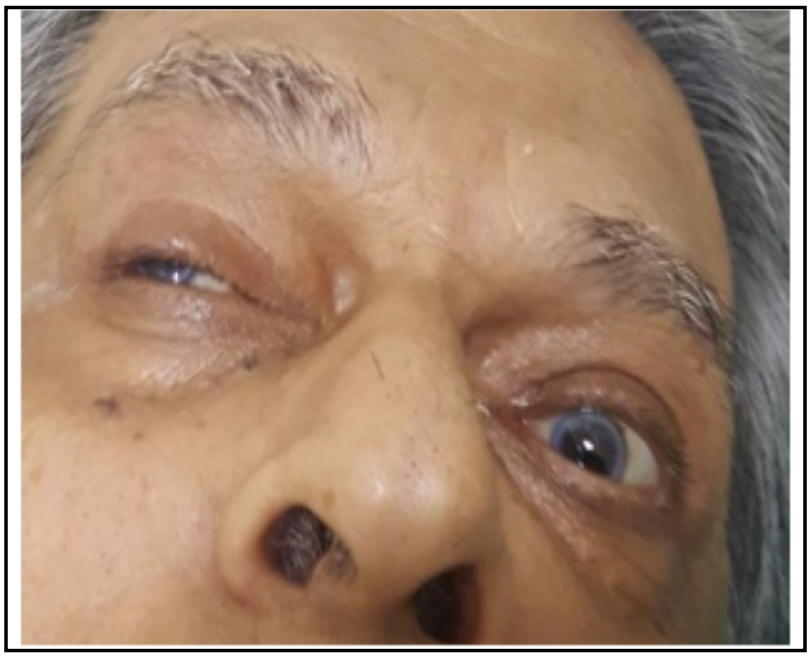

Fig. 1.Patient with 3rd cranial nerve palsy

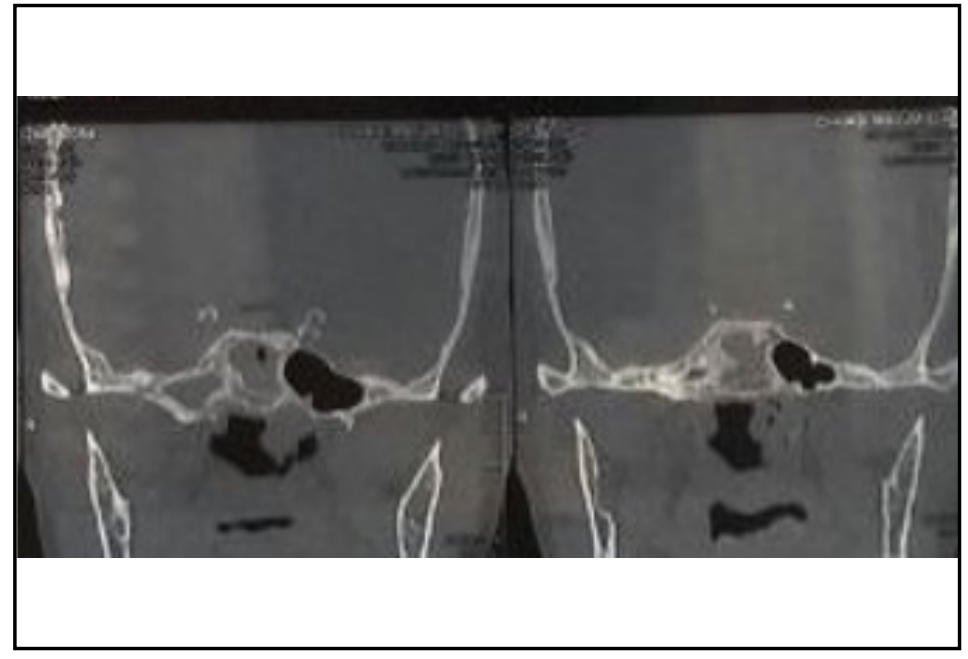

Fig. 2. CT scan suggestive of Sphenoid lesion under general anaesthesia and right sphenoid sinus was opened. A mucocele was found in the sinus. It was punctured and thick muco-purulent discharge was drained. The wall of the mucocele was removed. The right sphenoid sinus was thoroughly cleaned.

The patient's post-operative course was uneventful and he was started on broad spectrum antibiotics, decongestants and systemic steroids. The biopsy report of the tissue removed was sent for histopathological examination and showed to be sino-nasal mucosa with inflammatory changes. The orbital symptoms of the patients gradually improved and resolved completely within 15 days. (Fig. 4)

\section{Discussion}

Isolated sphenoid sinus lesions are rare occurring in just 2 to $3 \%$ of all paranasal sinus lesions. ${ }^{4}$ They include mucoceles, pyoceles and isolated mycotic infections. The sphenoid sinus is roughly involved in about $16 \%$ cases of chronic sinusitis. ${ }^{5}$ A sinus mucocele is defined as a mucous collection lined by the mucous secreting

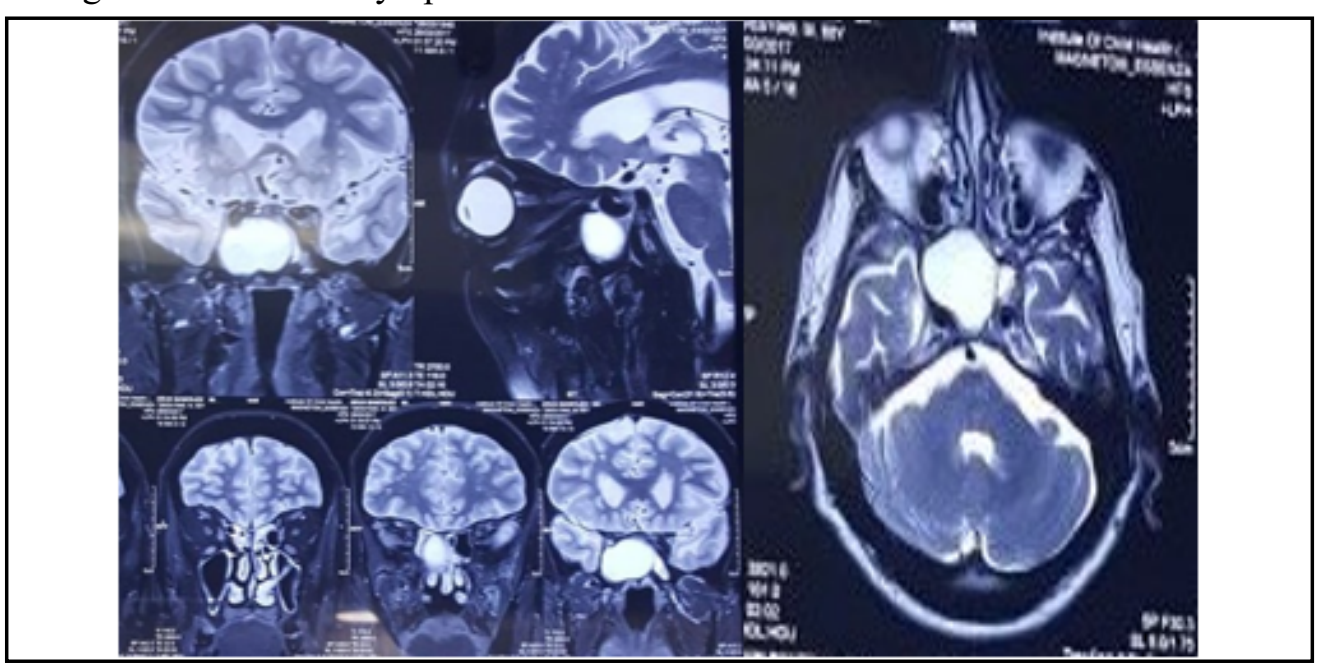

Fig. 3.MRI indicating sphenoid mucocele 


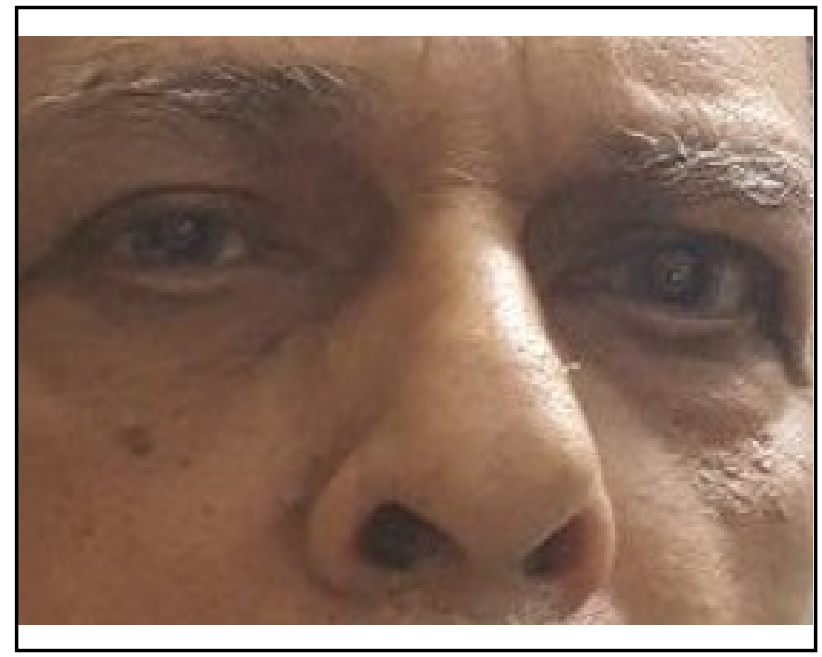

Fig. 4. Ophthalmoplegia improved within 15 days

epithelium of a paranasal sinus, occurring when a sinus ostium or a compartment of a septated sinus becomes obstructed. The obstruction is usually inflammatory in nature with tumour, trauma or surgery being the other causes. A pyocele is formed by the secondary infection of a mucocele. Skillern set forth several criteria for differentiating mucoceles from pyoceles, which include rate of growth, inflammatory symptoms, tenderness, consistency on palpation, severity of orbital symptoms, characteristics of contents of the cyst and the finding of pathogenic organisms on culture of this material. ${ }^{6}$

Clinically the most prominent findings are headache and a variable amount of secretion discharged through the sphenoid recess into the nasopharynx. ${ }^{7}$ However, orbital complications are not unheard of 3 but rare especially in this day and age, with features of unilateral proptosis, decreased vision, diplopia, and photophobia seen in the patient. ${ }^{8}$ Due to these symptoms, the patient often presents to the ophthalmologist as in our case prior to reporting to the ENT surgeon, affirming the need to have a good understanding of the disease among the ophthalmologists.

The clinical manifestations are variable and related to the direction of extension towards neighbouring structures. The most common clinical symptom is headache which is present in $70-80 \%$ of cases. ${ }^{9}$ This is typically retro-orbital. Visual disturbance is the second commonest group of symptoms making surgery necessary. ${ }^{10}$ The optic nerve is the most frequently involved cranial nerve with reduction in visual acuity. Palsy of eye movement with diplopia occur in 30$50 \%$ of cases. ${ }^{11}$ The oculomotor nerve is affected more frequently than the trochlear and abducens nerve as in our case. Oculomotor nerve involvement accounted for $70 \%$ of ocular palsies. ${ }^{11}$

Although sphenoid sinus mucocele is pathologically benign, it may involve many vital structures, including the dura, pituitary gland, optic nerve, cavernous sinus, internal carotid artery and cranial nerves (oculomotor, trochlear, trigeminal and abducent nerves) which are vulnerable to injury from the sphenoid lesion. Complications include diplopia, blindness, meningitis, cavernous sinus thrombosis and the compression of the internal carotid artery. ${ }^{12}$ This makes it essential to have an MRI done along with the CT scan as was done in our case to effectively manage the disease as urgently as possible.

Role of CT and MRI is paramount to the diagnosis of the Sphenoid mucoceles. The CT scan shows the affected sinus is completely opacified and the margins are expanded and usually thinned. ${ }^{13}$ Areas of complete bone resorption may be present, resulting in bony defect and extension of the 'mass' into adjacent tissues. Peripheral calcification is sometimes seen. Following administration of contrast, only peripheral enhancement (if any) is seen. The content of the sinus is variable, depending on the degree of hydration, ranging from near-water attenuation to hyperattenuating as secretions become increasingly thick and desiccated

MRI signal intensity is highly variable and depends on the proportions of water, mucus and protein 13:

T1 weighted images:

o water rich content: low signal (most common)

o protein rich content: high signal

T2 weighted images:

o water rich content: high signal (most common)

o protein rich content: low signal

MRI features in our case were suggestive of a rich protein content mucocele, compressing the structures near the right Orbital apex. Optic nerves, optic chiasm and retro-bulbar fat cones were normal. 
The recommended treatment of most mucoceles and pyoceles is surgical drainage by endoscopic sinus surgery. ${ }^{1,2,3}$ The sinus outflow tracts are preserved with minimal alteration of the anatomical architecture.

Not many cases have intracranial extension with the walls of the mucoele in most cases remaining intact. ${ }^{8,14}$ Even with intra cranial extension, ophthalmologic signs and symptoms may be absent and can be treated effectively with the nasal endoscope. ${ }^{4}$

Proper and timely treatment usually results in rapid regression of the ophthalmic manifestation, but vision seldom returns to normal in the case of visual dysfunction due to optic nerve compression with vascular compromise or extension of the sinus infection and inflammation to the optic nerve. A delay in surgery of more than seven to ten days after the onset of visual dysfunction is often associated with poor visual prognosis. ${ }^{15}$ Thus, the appropriate diagnosis must be made early, ${ }^{16}$ with rapid intervention to achieve good results and restoration of adequate eye movements. However El Mograbi ${ }^{17}$ noted that, there was resolution of ophthalmoplegia even when the intervention had occurred 2 months after the onset of visual problems, hence making it imperative to act whenever the patient presents to us.

\section{Conclusion}

The sphenoidal mucocele, though a rare entity which needs to be diagnosed and managed at the earliest. Patients with headache or other features of sinusitis associated with ophthalmic manifestations require an urgent diagnostic imaging (CT scan nose and paranasal sinuses with or without MRI) and the involvement of the Otorhinolaryngologist in the management of the disease. Nasal endoscopes have revolutionised and simplified the treatment of the sphenoidal mucocle with an adequate sphenoidotomy and drainage giving excellent results. Resolution of ophthalmoplegia is excellently achieved with the surgical procedure itself.

\section{References}

1. Singh D, Sohal BS, Aggarwal S. Isolated Sphenoid Pyocele with Thornwaldt's Cyst of Nasopharynx. Indian J Otolaryngol Head Neck Surg. 2011; 63(1): 140-1

2. Thane D, Cody R, Hallberg OE. Pyocele of the Sphenoid Sinus AMA Arch Otolaryngol. 1959; 70(4): 495-9. doi:10.1001/ archotol.1959.00730040505011

3. Ono Y, Ono G, Chigasaki H, Ishii S. Clinical manifestation of muco- and pyocele of the sphenoid and ethmoid sinuses. No Shinkei Geka 1975; 3(8): 681-9

4. Giovanetti F, Fillaci F, Ramieri V, Ungari C. Isolated sphenoid sinus mucocele: Etiology and management. J Craniofac Surg. 2008; 19(5): 1381-4. doi: 10.1097/SCS.0b013e31818437d6

5. Kennedy DW, Josephson JS, Zinreich SJ, et al. Endoscopic sinus surgery for mucoceles: A viable alternative. Laryngoscope 1989; 99: 885-95

6. Skillern RH. The Catarrhal and suppurative diseases of the accessory sinuses of the nose. Ed. 3, Philadelphia, J. B. Lippincott Company, 1920, p. 344. 19

7. Stammberger H. Functional endoscopic sinus surgery: the Messerklinger technique. Philadelphia: Decker; 1991. p. 208

8. Khademi B, Gandomi B, Tarzi M. A huge sphenoid sinus mucocele: Report of a case. Ear Nose Throat J. 2009; 88(5): E5

9. Sundar U, Sharma AL, Yeolekar ME, Pahuja V. Sphenoidal sinus mucocoele presenting as mono-ocular painless loss of vision. Postgrad Med J. 2004; 80(939): 40

10. Friedman A, Batra P.S, Fakhri S, Citardi MJ, Lanza DC. Isolated Sphenoid Sinus Disease: Etiology and Management. Otolaryngology- Head and Neck Surgery 2004, 133(4):544-50

11. Friedman G, Harrison S. Mucocoele of the sphenoidal sinus as a cause of recurrent oculomotor nerve palsy. J Neurol Neurosurg Psychiat. 1970, 33, 172-9

12. Bahgat M, Bahgat Y, Bahgat A. Sphenoid sinus mucocele. BMJ Case Reports. 2012; 2012: bcr2012007130. doi:10.1136/bcr2012-007130

13. Bell D, Gaillard F et al. Paranasal Sinus mucocele. https:// radiopaedia.org/articles/paranasal-sinus-mucocele.

14. Fujimoto K, Shimomura T, Okumura Y. A case of Sphenoid sinus mucocele. No Shinkei Geka 1999; 27(12):1129-32

15. Lee La, Huang CC, Lee TJ. Prolonged visual disturbance secondary to isolated sphenoid sinus disease. Laryngoscope 2004; 114: 986-99

16. Lee JC, Park SK, Jang DK, Han YM. Isolated Sphenoid Sinus Mucocele Presenting as Third Nerve Palsy. Journal of Korean Neurosurgical Society 2010; 48(4): 360-2. doi:10.3340/ jkns.2010.48.4.360

17. Mograbi AE, Soudry E. Ocular cranial nerve palsies secondary to sphenoid sinusitis. World Journal of Otorhinolaryngology- Head and Neck Surgery 2017; 3(1):49-53. https://doi.org/10.1016/j. wjorl.2017.02.001 